\title{
Innovative Delivery Of MBA Business Foundation Coursework: Does Integrated, Team Teaching Make A Difference?
}

\author{
Harry J. Lasher, (Email: hlasher@kennesaw.edu), Kennesaw State University \\ George E. Manners, (Email: gmanners@ kennesaw.edu), Kennesaw State University
}

\begin{abstract}
Team-teaching is often viewed as a viable alternative to traditional delivery approaches in graduate business programs. However there is little research to support the benefits of team-teaching from a student learning perspective. This paper demonstrates that student achievement in "downstream" $M B A$ courses is significantly improved when they complete integrated, team-taught business foundation courses.
\end{abstract}

\section{INTRODUCTION}

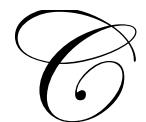

hange comes slowly in academic environments. We continue to see the use of "convenient traditional" classroom settings augmented in some instances with technology in undergraduate and graduate programs. Individual teachers continue to "control" the classroom and relish total autonomy with little exploitation of innovative possibilities to involve adult learners in defining and implementing a learning environment. Change is seldom sought on an incremental and/or system-wide basis and we continue to experience faculty resistance to innovation in designing and delivering courses in an integrative, team-teaching approach. In the few instances where experimentation in enhancing MBA student learning occurs, using integrative team teaching as an innovative organization design, it has had limited long-lasting success in academic settings. Lastly, there is little research which supports that students enhance their learning of business foundation information, as a result of team teaching methods, and achieve at higher levels throughout the remainder of their MBA programs.

\section{PURPOSES OF THIS PAPER}

The purposes of this paper are to: (1) explore what constitutes team teaching in academic settings, (2) describe integrated team teaching in the Career Growth MBA (CGMBA) program at the Michael Coles College of Business, Kennesaw State University, (3) describe the design of two innovative, integrative business foundation courses to address prerequisite requirements for entry into the core MBA program, and (4) analyze the academic performance comparing students completing these innovative courses to those entering the CGMBA without needing business foundation prerequisites.

\section{TEAM TEACHING IN ACADEMIA}

Some faculty and universities, responding to the growing interest in integrated and collaborative studies, are offering courses that integrate more than one discipline or subject, and in some cases, utilize the instruction of more than one professor. It should be noted, as well, that there are various terms referring to courses taught by multiple professors and/or represent more than one discipline or subject area. These courses may be identified by a variety of descriptions, such as cross-disciplinary, multidisciplinary, trans-disciplinary, interdisciplinary, or simply as a team- 
taught course, and each can denote a different measure of integration and collaboration of disciplines, topics, and instructors.

However, these classifications seldom address degrees of faculty cooperation and commitment in the design and delivery of knowledge, information, and skills. They also do not address the levels of learning that are desired if team-teaching is a desired delivery approach. Faculty may consider team teaching when desiring to help students move beyond knowledge and understanding levels of learning and want to focus upon applications, analysis, synthesis, and evaluation. (Hornyak \& Wenger, 1999). Faculty must explore team dynamics and team effectiveness criteria when engaging in the design and implementation of teaching teams. Interdependency, rather than independence, becomes operational throughout the process.

Course design and delivery varies from low to high levels of faculty collaboration (Benjamin, 2000). It is clear that varying levels of faculty commitment, in terms of time, egos, risk-taking, sharing of control and power, giving up classroom autonomy, colleague-student interaction, and so forth are heavily influenced by degrees of collaboration (Watkins, 1996). For example: Does everyone on the faculty teaching team plan all content and attend all classes? Is there a willingness to be challenged by other faculty as well as students? Do faculty engage in theoretical dialogue and try to "position" themselves against each other resulting in students assuming passive roles? Do faculty desire to appear periodically in classrooms, to "air-drop" content, and quickly retreat leaving integration and higher levels of learning to chance? Lastly, is it important that students be aware of the levels of collaboration that faculty used in conducting courses, particularly in the planning and assessment aspects of the courses? (Davis, 1995).

It is imperative that staffing of a team be voluntary. Faculty need to demonstrate accountability to themselves, other team members, and everyone in the adult learning community. Faculty need to model team leadership and effectiveness behaviors for other members in the learning community. At a minimum, faculty team members must have an understanding of their behavioral preferences, strengths and developmental needs, approaches to handling conflict, and comfort levels working in team settings. Emotional intelligence understanding is critical for faculty to interact effectively in a team-learning environment (Farnham, 1996; Goleman, McKee, \& Boyatzis, 2002; Shinn, 2003).

Competence, cooperation, coordination, commitment, trust and accountability are additional skill areas all team members should possess. Proactive use of technology to create a learning community and encourage information and experience sharing are important. In addition, listening, soliciting and providing feedback (George \& Davis-Wiley, 2000), involving others, and engaging in continuous professional development are among other "key" behaviors to ensure faculty team success.

It is important that faculty be willing to assume leadership roles, as well as follower roles, during the design and implementation phases of a team taught course. The issue is not style; rather it is substance. Faculty need to be able to influence and inspire everyone in the academic community to learn and enhance effectiveness in professional pursuits. They have to be willing to engage students, as well as each other, with an openness and experimentation of ideas and feelings. Team faculty need to be willing to listen, and encourage students and colleagues to analyze, synthesize, and evaluate. Lastly, team teaching requires being able to receive and provide feedback, not only related to content information, but in terms of behaviors and perceptions as well.

\section{INTEGRATED TEAM TEACHING IN THE CAREER GROWTH MBA (CGMBA) PROGRAM}

For the purposes of this paper, integrated team teaching is defined as a group of committed faculty, with different business discipline interests, designing learning experiences as a group, delivering materials in an integrative manner, engaging each other and students throughout the entire learning experience, and holding each other accountable for the evaluation of student learning effectiveness. Clearly this integrated, team teaching approach requires more faculty time and commitment to the learning process than other team approaches to designing and delivering innovative courses. For example, using electronic classrooms to encourage sharing of information and 
facilitation of discussions in timely ways requires committed faculty to continuously engage learners 24/7 throughout a semester.

\section{DESIGN AND DELIVERY OF TWO INNOVATIVE, INTEGRATED, BUSINESS FOUNDATION COURSES}

Prior to 2001, competitive forces resulted in an enrollment decline in the traditional MBA program at the Michael J. Coles College of Business, Kennesaw State University. Data (Green, 2001) indicated that in the period from 1992-1997 colleges and universities experienced an 11\% decline in undergraduate business degrees awarded while master's degrees in management increased $17 \%$. The discrepancy in business degrees awarded suggested that more non-business degree recipients were now seeking graduate degrees in business.

Traditionally, accredited AACSB MBA programs in the United States may require as many as eight to ten business foundation courses prior to allowing a student to matriculate into the graduate program. This is a significant burden for professionals pursuing an part-time MBA while maintaining full-time employment. Time is critical to this group of people who also have career aspirations, family responsibilities, travel challenges, and other demands upon their time. Clearly an approach to help this group of adult professionals engage in a more meaningful and relevant learning process could be mutually beneficial to the institution as well as the adult learners.

In addition, most introductory business foundation courses are not coordinated nor take into consideration what information is deemed important by "down-stream" faculty to enhance success in their courses. They are typically delivered in "isolated silos" of knowledge with little appreciation of applications or integration with the business environment professionals are engaged in.

A task force was convened, comprised of selected innovative and engaged faculty, to identify what information and knowledge "down-stream" faculty wanted students to have when entering their core business courses. This group canvassed colleagues teaching these courses, along with professionals in the business community, to identify critical information and knowledge areas. The task force quickly realized that there was an overlap of information and knowledge by business disciplines. The task force leader introduced the idea of "thinking outside the silos" considering what the business community, as well as colleagues, wanted from the "finished products" after they completed business foundation work.

The information and knowledge was grouped into two areas: (1) analytical business applications, and (2) contemporary business topics. Analytical business applications included financial accounting, finance, statistics, business plan development, and team leadership and development. Contemporary business topics included economics, management (i.e. leadership, managerial functions, organizational design, operations, and strategy), marketing, and team leadership and development. The task force recommended that a totally integrated and team approach be used for both students and faculty in addressing these two areas. Also an applied, integrative, "capstone" experience needed to be a critical part of the conclusion of each course.

Task force results encountered the traditional resistance often found in academic settings. Faculty preferred controlling their own "silo" courses. Faculty felt they were the sole determinants of what adult part-time students needed and often this was without input from the business community, adult professional learners, or an appreciation and understanding of the realities of workplace dynamics.

A few passionate change leaders emerged from the faculty ranks and recognized the opportunities to innovate and meet relevant learning needs of adult learners. Interestingly, these change leaders had extensive business backgrounds in major corporations as well as being very active consultants. Working together, and without concern for rewards and credit, they designed two six hour integrated courses with the prime objectives of preparing students for success in "down-stream" core MBA courses, as well as enhancing the career success of professional, adult learners. In addition, they were so committed to adult learner success that they committed to teaching the Analytical Business Applications course on Saturdays, 8 am to $1: 45 \mathrm{pm}$, and the Contemporary Business Topics course on Sundays, noon to 5:45 pm. In addition, they agreed to use WebCT as a technology platform to form an adult learning community and constantly engage adults in a professional learning setting. This integrated faculty team committed to 
engage in continuous improvement by constantly seeking feedback from the part-time adult learners. From the beginning of the courses, students were formed into learning teams, provided team skills, and encouraged to hold themselves accountable for their learning experiences.

Faculty hoped to see several things happen as a result of these innovatively integrated designed and delivered courses. First, students and faculty would learn from each other. Second, a greater percentage of adult learners would successfully master course materials and acquire/enhance skills for future success. Third, support networks developed in these courses would improve retention and satisfaction with the entire learning process. Fourth, it was hoped that adult learners would demonstrate higher levels of achievement compared to other CGMBA students who have not experienced the innovative, integrated, team delivered business foundation courses. Fifth, adult learners would be more satisfied with their learning experiences upon completion of their Career Growth MBA than those not experiencing the integrated, team taught business foundation courses. This satisfaction would be reflected in retention rates, future teaming efforts, and a support network throughout their CGMBA. Sixth, adult professionals would achieve greater career success by being able to directly apply theory, concepts and information after each class as well as extensive sharing of experiences within WebCT discussion forums.

Focusing upon academic achievement in the Career Growth MBA, the following hypothesis is evaluated: Is there a significant difference in the academic achievement of part-time adult learners who complete one or both of the business foundation courses compared to colleagues in their Career Growth MBA program who were not required to take business foundation courses because they had completed undergraduate business degrees?

\section{RESEARCH FINDINGS OF THE EFFECTIVENESS OF INTEGRATED FACULTY DESIGNED AND DELIVERED BUSINESS FOUNDATION COURSES}

Data was collected on all entering Career Growth MBA students entering KSU from Fall 2001 through Fall 2003. Performance of the students entering the integrative business foundation courses was then compared with that of the undergraduate business majors who did not take the foundation courses and went directly into the CGMBA. Table 1 shows the two populations in terms of entering descriptors.

\begin{tabular}{|lcccccc|}
\hline & \multicolumn{7}{c|}{ Table 1 } & & \\
& Entering Data From Fall 01 & Through Fall 03 & \\
Others & M & F & N & UG GPA & GMAT & Age \\
Foundation & 253 & 204 & 457 & 3.20 & 504 & 31.0 \\
& 175 & 91 & 266 & 3.18 & 514 & 32.6 \\
\hline
\end{tabular}

The data indicated that the integrative foundation students were slightly older and had a slightly higher GMAT score than the undergraduate business majors who entered the MBA program. The business foundation courses also had a higher proportion of males. Given the sample sizes, all of these differences are "statistically significant." However, on an overall basis, these two populations are not that far apart on a practical level.

The academic performance or achievement of the two populations in regular CGMBA classes can be described both in terms of grade point average as well as frequency distributions in Tables 2 and 3. 


\begin{tabular}{|lr|}
\hline \multicolumn{2}{|c|}{ Table 2 } \\
Population GPAs \\
Foundation & 3.540 \\
Others & 3.613 \\
\hline
\end{tabular}

\begin{tabular}{|lccccc|}
\hline \multicolumn{7}{c|}{ Table 3 } & & \\
& Grade Distribution By Population & & \\
Foundation & A & B & C & D & F \\
Others & $51.3 \%$ & $26.1 \%$ & $2.1 \%$ & $0.0 \%$ & $0.6 \%$ \\
\hline
\end{tabular}

While Table 2 is again statistically significant (given the sample sizes) but not necessarily practically important, Table 3 reveals a very significant tendency of the business foundation students to perform at the top levels in the classroom. The grade distributions are only for MBA courses beyond business foundation courses.

\section{FINDINGS AND CONCLUSIONS}

Clearly those adult professional learners completing one or both of the integrated, team taught courses displayed a higher achievement level compared to those directly entering the Career Growth MBA. An argument can be made that the integrative, team teaching approach could be extended to some of the core courses to help students enhance their learning and achieve competitive advantage throughout their careers.

Future research will be conducted to include spring 2004 entering students. Additional analysis will occur as more adult learners complete courses and graduate. For example, future research will address whether there is a significant difference in retention rates, graduation rates, and levels of satisfaction among the two groups of adult learners. These satisfaction levels will relate to comparing "traditional" classroom delivery of stand-alone courses with integrated, team taught classes.

\section{REFERENCES}

1. Benjamin, J. (2000). "The scholarship of teaching in teams: What does it look like in practice?" Higher Education Research \& Development, 19, 191-204.

2. Davis, J. R. (1995). Interdisciplinary courses and team teaching. Phoenix: Oryz Press.

3. Farnham, A. (1996, January 15). "Are you smart enough to keep your job?" Fortune, 35-48

4. George, M. A., and P. Davis-Wiley (2000). "Team teaching a graduate course". College Teaching, 48, 75-80.

5. Goleman, D., A. McKee, and R. E. Boyatzis (2002). Primal leadership: Realizing the power of emotional intelligence. Boston: Harvard Business School Press.

6. Green(2001) "Up, down, and all around: Enrollment trends in management education", MBAR Roundtable Journal,2,7-14

7. Hornyak, M., and M. Wenger (1999). "Team teaching for higher-level learning: A framework of professional collaboration". Journal of Management Education, 23, 311-328.

8. Shinn, S. (2003, September/October). BizEd, 19-23.

9. Watkins, T. (1996). "Stage I: Creating a new MBA core with team teaching". Journal of Management Education, 20, 411-421. 
NOTES 